\title{
Professional learning through the collaborative design of problem-solving lessons
}

\author{
Geoff Wake $^{1} \cdot$ Malcolm Swan ${ }^{1} \cdot$ Colin Foster $^{1}$
}

Published online: 18 November 2015

(C) The Author(s) 2015. This article is published with open access at Springerlink.com

\begin{abstract}
This article analyses lesson study as a mode of professional learning, focused on the development of mathematical problem solving processes, using the lens of culturalhistorical activity theory. In particular, we draw attention to two activity systems, the classroom system and the lesson-study system, and the importance of making artefacts instrumental in both. We conceptualise the lesson plan as a boundary object and use this to illustrate how professional learning takes place through the introduction of carefully designed artefacts that draw on teachers' professional knowledge of potential student approaches, and to the nature of progression in problem-solving processes. We identify the roles of instrumentalisation and instrumentation in supporting professional learning as these artefacts are prepared for use before a lesson and as they are again used as catalysts for reflection in post-lesson discussions. These artefacts are seen to effectively facilitate the socially situated learning of all participants. We conclude that the design of artefacts as boundary objects that support teaching and professional learning in their respective activity systems may be fundamental to the success of lesson study as a collaborative venture.
\end{abstract}

Keywords Cultural-historical activity theory $\cdot$ Lesson study $\cdot$ Problem solving $\cdot$ Task design

Geoff Wake

geoffrey.wake@nottingham.ac.uk

Malcolm Swan

malcolm.swan@nottingham.ac.uk

Colin Foster

colin.foster@nottingham.ac.uk

1 Centre for Research in Mathematics Education, School of Education, University of Nottingham, Jubilee Campus, Wollaton Road, Nottingham NG8 1BB, UK 


\section{Introduction}

This article addresses the role that designed artefacts can play in the professional learning of teachers when embedded in a lesson-study process. Our intention is to explore how this process might facilitate the professional learning of individuals and communities of teachers and academics. In doing this, we draw on cultural-historical activity theory (CHAT) to make sense of the interplay between research lesson classrooms and lessonstudy planning groups (which include both teachers and academics from Higher Education who have multiple roles as lesson designers, researchers, and authors of this article). This provides insight into how the lesson plan and specially designed features of this play a critical role that supports the development and enactment of problem-solving lessons and teacher learning in relation to this.

The research reported here is situated within a broader project (Wake et al. 2013, 2014; Foster et al. 2014) that has two aims:

1. To better understand how models of professional learning for secondary school teachers, based on lesson study, may be developed and sustained within current and changing systems and structures of school governance and funding mechanisms;

2. To develop, using an action research methodology, tools that assist collaborative partnerships to implement lesson study on mathematical problem solving, in ways that are effective, sustainable, and scalable.

The analysis central to this article arises from our ongoing efforts to address the second of these aims. In particular, we report here on research focused on the question: How do we support and facilitate teachers in their dual roles of teacher and learner? In seeking to address this question, we are engaged in participatory action research (Kindon et al. 2007) into how we might better facilitate lesson-study groups to plan for collaborative classroom problem solving, and thus inform our collective understanding of how didactical design intentions are realised in implementation. This form of research is driven by:

a collective commitment to investigating an issue; a desire to engage in self and collective reflection to gain clarity about the issue; a joint decision to engage in collective action that leads to a useful solution that benefits the people involved; the building of alliances between researchers and participants in the planning, implementation and dissemination of the research process (McIntyre 2008).

The lesson-study process in our study involves a series of research lessons planned by a community of teachers drawn from each of several clusters of schools. In the first year, our research involved three to four teachers at each of nine schools organised into two clusters (of four and five schools) in different parts of England. Each school developed three research lessons, which were attended by teachers from schools across the same cluster and by other outside academics. In our research role, we adopted a case study methodology in order to obtain rich, contextual data to inform a CHAT analysis. The data drawn upon in developing case studies consist of video recordings of the planning meetings, research lessons, and post-lesson discussions; email correspondence in relation to lesson planning between researchers, teachers, and others; researcher records of students' work in research lessons; and audio recordings of interviews with teachers and other participants. The work we present as illustrative here focuses on a single case study, one of the 27 that were developed. In general, a case is centred on the process of planning, conducting, and discussing a single research lesson. 


\section{The lesson-study process}

Fundamental to the various models of lesson study that have proliferated around the world in recent years (Fernandez and Yoshida 2004) is the concept of professional learning focused on teacher enquiry into teaching, learning, and classroom practice. Teachers collaborate and learn through cycles of enquiry into their practice, and this provides unique opportunities for researchers to investigate how teachers learn through the process of developing, adapting, mediating, and reflecting on lesson plans. Throughout our study, we have been fortunate to be able to work with colleagues from IMPULS in Japan ${ }^{1}$ who, operating in their own culture of well-established lesson-study communities, were at the same time, in reaction to developments in the Japanese curriculum, beginning to tackle similar issues to us in relation to problem solving. Lesson study based on the Japanese model has become increasingly widely known and adapted for use across geographical and cultural boundaries since the publication of Stigler and Hiebert's book The Teaching Gap (1999). The model is perhaps particularly attractive as it has the potential to meet the requirements that we know facilitate effective professional learning (Joubert and Sutherland 2009); namely, that it is sustained over substantial periods of time, collaborative within mathematics departments/teams, informed by outside expertise, evidence-based, research-informed, and attentive to the development of the mathematics.

As Doig and Groves (2012) point out, there is a need to adapt rather than adopt the Japanese model when working in another culture. However, in our work, we maintained what we saw as crucial aspects of the Japanese model. Teachers first met with a 'knowledgeable other' to identify one or more specific research questions to be answered in the lesson and prepare a detailed lesson plan that included anticipating student responses and learning trajectories. The research lesson was then observed by a community of the teachers and academics, and this was immediately followed with an extended post-lesson discussion in which the research questions were explicitly addressed, assisted by a 'knowledgeable other'. Fundamental to our model, therefore, were (i) the focus on learning with materials (kyozaikenkyu), as planned and enacted by the teacher, (ii) the mathematical experiences and learning of students, and (iii) the expertise brought to the communities by 'knowledgeable others' (koshi) (Lewis et al. 2006). Throughout the activity of the lessonstudy group, the lesson plan as a document was central. Developed as a communicative production, it embodied a shared understanding of teaching and learning intentions. Indeed, the lesson plan provided individuals in the group and the group as a whole with an image of the intended lesson (Roth and Radford 2011). Further, in the post-lesson discussion, the group reflected on the enactment of the plan in relation to this prior image.

We wanted to expand notions of professional learning, recognising that for teachers, as for other workers, it is a process that includes ongoing, moment-by-moment reflection on action (Schön 1983). Lesson study, like other forms of formalised professional development activities, attempts to make specific aspects of professional learning explicit and provides both time and space in which this can occur and be shared with colleagues, as opposed to day-to-day professional learning that is often individual, ad hoc, and tacit.

While the lesson-study process may lead to the collaborative development of a revised version of the lesson plan and a further lesson-study cycle (planning, research lesson, postlesson discussion), we do not regard an improved individual lesson plan as the main

\footnotetext{
${ }^{1}$ IMPULS is a project at Tokyo Gakugei University, funded by the Japanese government, that aims to establish teacher development systems for long-term improvement in mathematics instruction. For more details see www.impuls-tgu.org/en/about/about_outline.html.
} 
outcome. Rather, we consider the process as facilitating teachers' (and our own) learning about didactical design more generally, beyond that of a single and particular lesson. Thus, our intention is to investigate how best to support teacher groups involved in iterative cycles of action research into their design of lessons for mathematical problem solving.

\section{Problem solving}

In our research, a mathematical problem is defined as a task for which a solution method is not known in advance by the solver (NCTM 2000). The OECD PISA series of international comparative studies that quantify student performance on a range of tests in mathematics, and also science and literacy, have raised the profile of problem solving around the world. The framework used by these studies to define the mathematics domain (OECD 2003), in addition to content, identifies competencies and context and how these blend together in the mathematics tasks which are given to students, thus recognising the mathematical practices in which students then engage. In seeking to help students become better mathematical problem solvers, our lesson-study communities are therefore attempting to focus on developing mathematical processes rather than mathematical concepts. In short, we are attempting to enable students to use the mathematical content they already know in non-routine problems. In England, this was elaborated in the National Curriculum for Mathematics of 2007 (Qualifications and Curriculum Authority 2007), which organised these 'key processes' using a problem-solving cycle incorporating the terms 'representing' (translating problems into mathematical form), 'analysing', 'interpreting', and 'evaluating', with overarching competencies identified as 'communicating' and 'reflecting'. It has been the experience of the teachers in our study that it has been very hard to focus on these mathematical problem-solving processes in lessons. National and school-based constraints mean that day-to-day classroom practice is almost entirely concept-oriented (Foster et al. 2014). Indeed, in early stages, our research identified limitations in teachers' understanding of the key processes as potentially detrimental to students' learning. This situation is not unique to the UK; for instance, it lies at the heart of our collaboration with the Japanese group IMPULS.

In the next section, we introduce a theoretical lens, cultural-historical activity theory, and the associated constructs of artefact, tool, and instrument, to identify how aspects of our lesson-study process facilitate professional learning. Important here are ideas relating to interacting Activity Systems and the boundaries between these. Following this, we illustrate how these ideas provide insight into our research question through one of our case studies. In the final sections of the paper, we draw conclusions in which we highlight important features of collaborative design of lessons for problem solving that facilitate professional learning for teachers and academics.

\section{A cultural-historical activity theoretic perspective}

Underpinning our theoretical thinking regarding lesson study as an effective mode of professional learning is cultural-historical activity theory. We use the theoretical tools that CHAT provides to better understand how we, as designers of professional learning, working with teachers as co-designers of lessons, might facilitate the professional learning process.

CHAT considers how the activity of a community, viewed as an activity system, is mediated by a range of factors. It builds on the fundamental thinking of Vygotsky about 


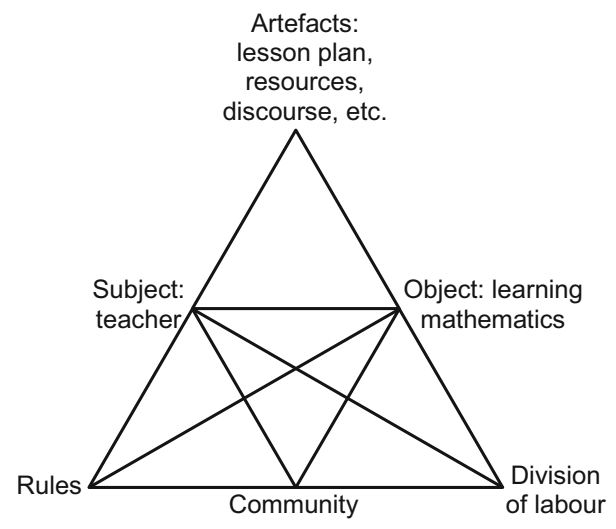

Fig. 1 Activity system

how the actions of an individual (subject) in pursuit of a goal-directed outcome are mediated by artefacts/tools as 'instruments'. This is represented by the top triangle in Fig. 1. Distinctions between the use of these terms are explored in some detail below, as they have significance in our conceptualisation of professional learning in the lesson-study process. Luria, Leont'ev, and followers, in considering the unit of analysis to be extended to a collective of individuals, identify the additional mediating influences of the community, with its division of labour and rules and norms, as indicated by the lower triangles in Fig. 1 (see Engeström and Cole 1997).

Thus, the mathematics classroom, considered as an activity system, has both teacher and students working towards the learning of mathematics: the object of their activity. If we consider the teacher as subject in this activity system, then we consider that their actions are mediated by a number of artefacts used at their discretion. For example, the teacher will have planned to use a range of resources and oral questions, will have sequenced different phases of the lesson according to their understanding of what will best facilitate learning of the particular group of students, and so on. Drawing a clear distinction between the use of the terms artefact and tool is not of particular importance here, and we note that there is not general agreement amongst scholars about their exact meaning in relation to Vygotsky's intentions (for discussion of this, see Daniels 2001, pp. 17-20). Here, for convenience, we use the term artefact throughout to encompass all such mediating factors; these include, for example, material objects, ideas, and language. In many instances in the classroom, access to artefacts is controlled by the teacher, for example the written tasks that are selected by the teacher to stimulate learning, the texts, manipulatives, technology, mathematical techniques, and representations. How the mediating artefacts are made instrumental in action, and how the teacher facilitates students in developing their conceptual understanding so that this might occur, is central to teaching and learning.

We wish to draw attention to the notion of instrument and its role as explicated and contextualised in the case of mathematics by Drijvers and Trouche (2008). They make the distinction between artefacts as having only the potential to support actions, whereas it becomes instrumental in its use when the user has a mental scheme that supports both technical and conceptual abilities to realise this potential in a specific situation. For example, a graphing calculator as an artefact can be considered as a material object incorporating graphing facilities that has the potential to be used to plot bivariate data and give the equation of the line of best fit. For this to become instrumental in use in a 
particular situation, the user must understand both the potential and the appropriateness of doing so and have the technical expertise and conceptual understanding to do this. In our study, the lesson-planning team's research questions in general focus on this issue: how can we enable students to bring artefacts to instrumental use as they tackle unstructured problems?

The lower triangles in Fig. 1 illustrate how the teacher's actions are situated within the classroom community and highlight key factors that will affect the joint activity of the group. For example, there is a clear division of labour in the classroom, with the teacher having overall responsibility to ensure that the outcomes of the group's activity meet expectations with regard to learning. However, the power relationship between teachers and pupils varies from one classroom to the next, with students having more or less autonomy towards their learning. Thus, the group as a whole develops a sense of community, which we might perceive as more or less collaborative, with the group's activity being constrained by explicit and implicit rules. For example, lessons are scheduled at certain times and are of predetermined length; curricula and schemes of work need to be complied with, assessment tasks worked on, and so on. Implicit rules include shared understandings of expectations of teachers, students, their parents, and the public more widely, including expectations regarding the form, style, and types of mathematical knowledge that are to be developed. Thus, implicit and explicit rules govern patterns of behaviour of the community in lessons on a day-to-day basis. In relation to this, we found that the introduction of lessons that focused entirely on mathematical problem-solving processes ran contrary to the expected norms in the classrooms of our study, and students had to reorient their expectations regarding the format of mathematics lessons. Thus, we consider that the actions of all individuals, as members of a community working towards a shared outcome, are affected by issues of division of labour, community, and rules.

Teachers in their professional lives are members of multiple communities: they are involved in many Activity Systems, determined by, amongst other factors, the structural organisation of their school and the educational system more widely. For example, mathematics teachers in secondary schools are frequently organised to work collectively in distinct departments in pursuit of the learning of mathematics. They also participate in wider communities, such as professional associations. In such communities, individual teachers are involved in different actions from those that they carry out in classrooms; for example, they may have a role in developing a scheme of work that organises the curriculum for the group of teachers with whom they work. Lesson study brings into the shared experience of teachers and other academics a new Activity System with the object of professional learning. The joint activity of the lesson-study group defines its 'membership': in our model of lesson study, this includes teachers from schools across the cluster, including the classroom teacher of the research lesson and ourselves as both codesigners of the research lesson and researchers. Individuals in the group take different roles during the distinct phases of activity that occur cyclically over time: developing the lesson plan, teaching and observing the research lesson, taking part in the post-lesson discussion, and (sometimes) refining the lesson plan. This new Activity System has its own distinctive division of labour, sense of community, and rules that mediate both the joint activity and individual actions of participants.

In relation to lesson study, therefore, we have two Activity Systems of learning to consider: one centred on the learning of students in the research lesson classroom and the other centred on teachers and academics and their professional learning in the lesson-study community (Fig. 2). Third-generation Activity Theory (Engeström 2001) considers such interacting activity systems, and the very fact of their interaction draws our attention to 


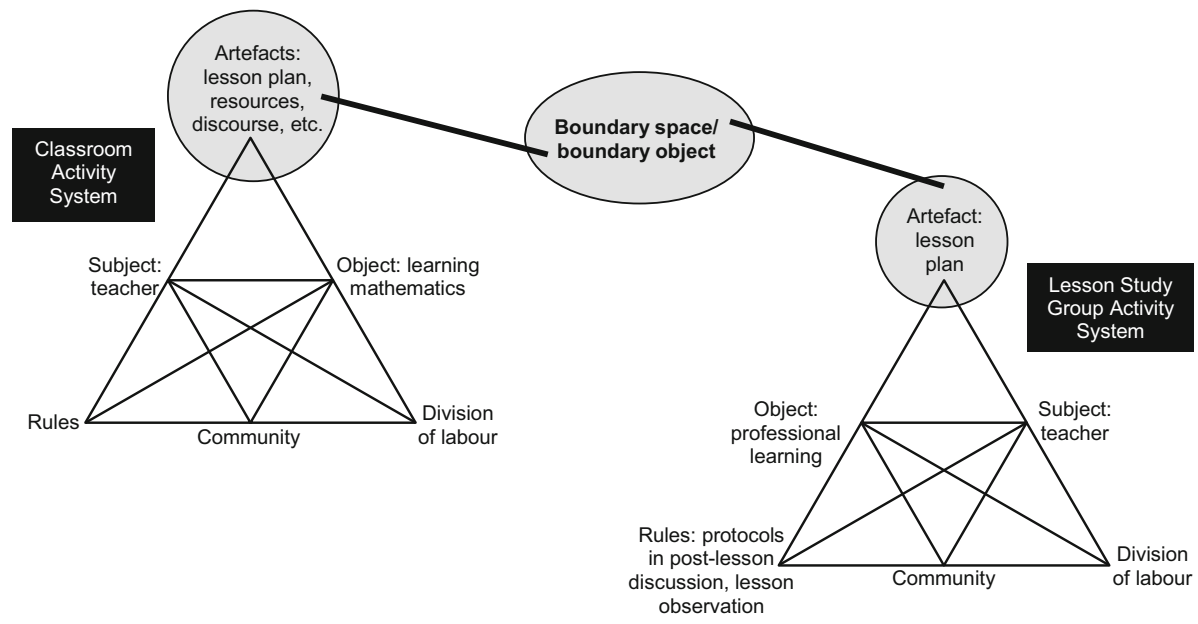

Fig. 2 Interacting activity systems of classroom (student learning of mathematics) and lesson-study group (professional learning)

boundary crossing. Because members of the lesson-study community are active in each of the communities of classroom and lesson-study group, they can be considered as boundary crossers between the two. Here, we draw on the notion of boundary as expressed by Akkerman and Bakker (2011, p. 133) 'as a sociocultural difference leading to a discontinuity in action or interaction'. In their review of research into boundary crossing and boundary objects, they argue that from a sociocultural perspective, all learning involves boundaries, although they recognise that researchers use the term in different ways. Here, we emphasise the importance of discontinuity at the boundary between Activity Systems as crucial in facilitating reflection on individual actions and joint activity in each, leading to professional learning for all participants. Indeed, in sociocultural terms, learning may be considered as being located in the changing relationships between an individual and the social activities in which they engage (Beach 1999). In other words, the professional learning of the teachers requires their engagement in, and boundary crossing between, the Activity Systems of the research lesson classroom and the meetings of the lesson-study group. We note that it is the object of activity that defines the boundaries of the activity system rather than geographical or temporal location. So, for example, when members of the lesson-study group observe teaching and learning in the research classroom, members' actions (other than those of the class teacher) are directed towards goals associated with the lesson-study group (i.e. the group's research questions) rather than those of the mathematics class, although that is where they are physically located. Our challenge is to understand how we might best support learning at the boundaries of classroom and lessonstudy group Activity Systems; indeed, how we might design for effective boundary crossing.

The lesson plan plays a critical role in facilitating this boundary crossing and consequent learning and, as such, may be considered a boundary object. Star and Griesemer (1989) define a boundary object as a single object that has different meanings in different Activity Systems, while retaining a common essence. They identify such objects as inhabiting 'several intersecting worlds' and being 'both plastic enough to adapt to local needs and the constraints of the several parties employing them, yet robust enough to 
maintain a common identity across sites' (Star and Griesemer 1989, p. 393). We see the lesson plan as being just such an object, as it is at the nexus of understanding of teaching and learning intentions, and as such has an important role to play in both the classroom and the work of the lesson-study group as well as being a catalyst for professional learning. In the classroom, the lesson plan acts as a mediating instrument by providing a script around which the research lesson is organised, whereas in the activity of the lesson-study group, it has other roles to play. At the beginning, the production of a lesson plan is the central activity of the group. The resulting artefact encapsulates the values, understandings, beliefs, and intentions of the group, with pedagogic tools, such as questioning for formative assessment, identified. In the post-lesson discussion, it acts as a mediating device for the discussion of the group, encapsulating the group's image of the intended lesson. It facilitates the group's discussion of these intentions, in the light of their observations of the resulting enactment in the classroom. The lesson plan, as a boundary object, therefore, facilitates reflection on action and perspective-making and taking (Boland and Tenkasi 1995) on issues in relation to teaching and learning. Engeström et al. (1995) show how such artefacts are commonly involved where activity systems interact, as textual artefacts emerge in ways that facilitate boundary crossing over time.

\section{Case study: Outbreak}

We now detail one case study that illustrates the three important phases of the lesson-study cycle (planning, research lesson and post-lesson discussion) before analysing this through the theoretical lens and constructs we have introduced above.

\section{Planning}

The school planning team of three teachers, supported by the authors of this article, collaboratively devised the lesson plan. The lesson was inspired by Outbreak, a mathematical problem-solving project (Knights and Zorn 2008). This is based on some of the dilemmas that health officials face when confronted with the outbreak of a deadly viral infection. Students are asked to develop a strategy to contain the spread of the disease. The lesson-planning team developed a lesson that involved students in deciding how to allocate two different vaccines amongst the population of a town. In this task, students were to be given the cost of each vaccine (£8, 66.50 ), their percentage effectiveness (90 and $70 \%$ respectively), and a total budget ( $£ 5 \mathrm{~m}$ ). They were also to be provided with additional data relating to the population of 946,000 , which was broken down into occupations such as 'medical workers' and 'farmers and food producers', with the numbers in each category given. Students were to recommend how many of each vaccine should be bought and who should get them. The basis on which students were to make these decisions was not to be specified; this was to be left open for students.

Collaborative lesson planning began 3 weeks before the research lesson was due to take place. In advance, we (the authors) had suggested a framework for structuring a problemsolving lesson, drawing on the Japanese model: hatsumon (the teacher gives the class a problem to initiate discussion); kikan-shido (the students tackle the problem in groups or individually); neriage (a whole-class discussion in which alternative strategies are compared and contrasted and in which consensus is sought); and finally the matome, or summary (Fernandez and Yoshida 2004; Shimizu 1999). The lead teacher, who was to 
Table 1 How teachers planned to modify the constraints part way through the lesson

\begin{tabular}{|c|c|c|c|c|}
\hline & \multicolumn{2}{|l|}{ Initial problem } & \multicolumn{2}{|c|}{ Modification to the constraints } \\
\hline & Vaccination A & Vaccination B & Vaccination A & Vaccination B \\
\hline Effectiveness & $90 \%$ & $70 \%$ & $100 \%$ & $70 \%$ \\
\hline Cost & $£ 8.00$ & $£ 6.50$ & $£ 12.00$ & $£ 5.20$ \\
\hline
\end{tabular}

teach the lesson, proposed a specific research focus on two problem-solving processes that he felt that his students particularly needed to develop: strategic planning and communication. The research questions for this lesson were then agreed by the planning team to be: Which classroom teaching interventions are effective in developing students' capacity to (a) plan strategically? (b) communicate their reasoning and methods more effectively?

To explore these questions, the lead teacher proposed that he should modify the constraints of the task part way through the lesson to see whether this would encourage students to adapt their existing strategies or whether they would simply start again. He also believed that this approach might give new insight into the problem and encourage greater discussion and collaboration. To develop students' planning strategies, he would also develop questions to encourage metacognitive behaviours that might help students to step back and evaluate their progress from time to time. These ideas were further developed with two of his colleagues. Together, they proposed to change the values of effectiveness and cost of the two vaccines as shown in Table 1 .

An early draft of the lesson plan was sent to the authors of this article for comment. We made three major suggestions:

- We were at first unclear as to why a change in constraints was necessary, and challenged this, suggesting that it might be overambitious.

- We suggested that as part of the planning process, the teachers try to anticipate the possible solution strategies that the class might use.

- We challenged the teachers to be explicit about how they would recognise student progress in their two research foci: strategic planning and communication.

The first suggestion encouraged the teachers to clarify their reasons for changing the constraints, and the teachers decided to retain this aspect. The teacher of the research lesson commented after the lesson on his reasons for doing so:

I feel the right decision was taken during planning to slightly update the task for the students during the research lesson as this added another dimension to the lesson. I feel the change made it more realistic and it also meant that all of the students when working in pairs needed to start from scratch and apply their collective thoughts to a modified version of the original task, meaning that no student's original attempt would just be replicated if there was a dominant member of a pair (Teacher, Outbreak lesson).

In response to the second suggestion, the teachers said that they found it difficult to anticipate student reasoning, and so they adopted a strategy to provide them with evidence. They decided to introduce the class to the initial problem in advance of the research lesson and allow students 20 min to tackle the task individually, unaided (the pre-lesson phase). They then collected the student responses and analysed these in order to inform the later stages of the planning of the research lesson, making decisions, for example, about student groupings. The teachers also developed a detailed list of key issues that had arisen, and 
Table 2 Anticipated issues: teachers' observations and predictions of the difficulties students would have with the problem and possible feedback questions

\begin{tabular}{|c|c|}
\hline Anticipated issues & Suggested questions and prompts \\
\hline $\begin{array}{l}\text { Students start detailed calculations before planning } \\
\text { an approach }\end{array}$ & $\begin{array}{l}\text { Describe in words a plan for tackling this problem } \\
\text { What are the key decisions you have to make? }\end{array}$ \\
\hline $\begin{array}{l}\text { For example, they start at the top of the list and } \\
\text { calculate the cost of vaccinating medical workers, }\end{array}$ & $\begin{array}{l}\text { Which information are you going to focus on at the } \\
\text { start; which will you ignore? }\end{array}$ \\
\hline
\end{tabular}

then move to next row, etc

Students ignore one or more constraints

For example, they forget that they only have $£ 5$ million budget, or that they only need 946,000 vaccines

Students do not justify decisions made

For example, they state a solution with no explanation

Students leap to conclusions

For example, they quickly assume that only vaccine A should be used because it is most effective; or only vaccine B should be used because it is cheapest

Students do not understand the concept of a budget

For example, they assume a good solution will be a cheap solution and do not realise they need to spend the whole budget to save the most lives

Students overwhelmed by the large numbers

For example, if they spend $£ 4.8$ million of the budget, they might believe that is close enough to their maximum and not appreciate that with $£ 200,000$ you could save many more lives

Students do not grasp the meaning of their calculations

For example, students might perform a sensible calculation but not understand what their answer represents

Students only write numbers with no justifications

Students do not understand the effectiveness of each vaccination

For example, students might not be able to grasp the idea of something being $70 \%$ effective

Students are confused between numbers representing money and people

For example, students might perform a calculation and get the solution 12,500 , but not know whether this is people or money
Do you have enough resources for your solution?

Have you made enough vaccine for everyone?

Have you wasted any money?

Have you wasted any vaccine?

Why have you chosen to allocate the vaccines in this way?

How can you be sure this is the best solution?

Have you taken all the issues into account?

Could you vaccinate more people if you used some of vaccine $\mathrm{B}$ ?

Could you save more lives if you used more of vaccine $\mathrm{A}$ ?

What is your main objective when trying to solve the problem?

Are there any more lives that you could possibly save?

How much money do you have remaining in your budget?

How many more vaccines would you be able to purchase with this amount of money?

What does this figure represent? Is it how much money is left over or how much money has been spent? Does it represent a number of people?

Where have these figures come from? Do you know what they represent? Are you able to justify why you have used these numbers?

If 1000 people were given vaccination $\mathrm{B}$, how many would be likely to survive?

Can you think of a way of distinguishing between numbers that represent different values?

How can you distinguish between values that represent people or money?

produced questions showing how the teacher of the research lesson might respond to each (Table 2). The teacher used this table to write suitable questions on each student's work at the end of the pre-lesson phase, to prompt them to reflect more deeply on the approach they were taking. (No grades or evaluative statements were written on students' work.) In response to the third challenge, we worked with the teachers to try to describe how progression might be recognised, using a progression table (Table 3). Drawing on our 
Table 3 Progression table: an outline of different levels of achievement with suggested questions to support students' progress

\begin{tabular}{|c|c|c|}
\hline & Strategic approach & Communication \\
\hline Little progress & $\begin{array}{l}\text { Attempts to work towards a solution by } \\
\text { carrying out operations with figures but } \\
\text { shows little strategic awareness that will } \\
\text { lead to a solution }\end{array}$ & $\begin{array}{l}\text { Begins to represent the problem using only } \\
\text { numbers, without indication of what } \\
\text { these represent } \\
\text { Does not offer any explanation of what is } \\
\text { happening }\end{array}$ \\
\hline $\begin{array}{l}\text { Questions for } \\
\text { progression }\end{array}$ & $\begin{array}{l}\text { Can you write down an action plan as to } \\
\text { how you are going to complete the task } \\
\text { effectively? What are the other pieces of } \\
\text { information you need to consider? }\end{array}$ & $\begin{array}{l}\text { What do each of these numbers represent? } \\
\text { Can you think of a way of making it } \\
\text { clearer for someone else who looks at } \\
\text { your work to understand what you are } \\
\text { doing? }\end{array}$ \\
\hline Some progress & $\begin{array}{l}\text { Carries out appropriate and correct } \\
\text { calculations but does not take constraints } \\
\text { into account }\end{array}$ & $\begin{array}{l}\text { Calculations are clear, giving correct units } \\
\text { (e.g. } f) \text {, but fail to communicate the } \\
\text { reasons behind the calculations }\end{array}$ \\
\hline $\begin{array}{l}\text { Questions for } \\
\text { progression }\end{array}$ & $\begin{array}{l}\text { Are there other pieces of information you } \\
\text { have not thought about? }\end{array}$ & $\begin{array}{l}\text { What are the reasons behind the decisions } \\
\text { and calculations you have made? }\end{array}$ \\
\hline $\begin{array}{c}\text { Substantial } \\
\text { progress }\end{array}$ & $\begin{array}{l}\text { Works towards a solution logically, } \\
\text { reaching a viable solution }\end{array}$ & $\begin{array}{l}\text { Uses inefficient methods to communicate } \\
\text { ideas (e.g. long essay answers, rather than } \\
\text { a two-way table) }\end{array}$ \\
\hline $\begin{array}{l}\text { Questions for } \\
\text { progression }\end{array}$ & $\begin{array}{l}\text { Can you think of an alternative approach to } \\
\text { solving this problem? What would be the } \\
\text { effect on the outcome? }\end{array}$ & $\begin{array}{l}\text { Can you think of a more efficient way of } \\
\text { displaying this information that will make } \\
\text { your thoughts easier to follow? }\end{array}$ \\
\hline $\begin{array}{l}\text { Task } \\
\text { accomplished }\end{array}$ & $\begin{array}{l}\text { Arrives at a solution having considered } \\
\text { alternatives }\end{array}$ & $\begin{array}{l}\text { Communicates clearly their solution in a } \\
\text { variety of formats, selecting the most } \\
\text { appropriate format for what is aiming to } \\
\text { be achieved (e.g. a two-way table, a } \\
\text { letter) } \\
\text { All reasons are clearly explained and } \\
\text { justified, using logical arguments }\end{array}$ \\
\hline
\end{tabular}

1. Individually, students recall the problem and respond to the teacher's comments.

2. In pairs, students compare their methods. Students share progress so far with a partner, including the reasoning behind the decisions made.

3. New challenge introduced. The constraints of the problem are changed and students are given a poster to facilitate sharing. The teacher assesses conversations and intervenes with the prepared questions.

4. Whole-class sharing (neriage) in which the teacher selects pairs of students to present their ideas and reasoning, while others in the class assess this

5. Summarising and reflecting in which the teacher focuses on the strategic differences between solutions and draws out from the class some general learning points. For example: "It is better to address the total vaccines available before deciding who receives them, rather than allocating them, then finding that the budget has been exceeded." "A table is a powerful way of organising data, but may not be the only way."

Fig. 3 Structure of research lesson proposed by the teachers

previous work in lesson design, we provided a structure for this and co-constructed the content in collaboration with the teachers in the lesson-study group. This table was particularly useful in focusing attention on the research questions.

The final plan of the lesson contained the following elements: a description of the class; the research aims of the lesson; the anticipated issues and progression tables; an outline of the lesson itself, giving times, activities, interventions and questions, and anticipated responses from students. Broadly, the plan followed the structure shown in Fig. 3. 


\section{The lesson}

The students were a high-attaining class aged 11-12 within a mixed 11-18 comprehensive school in the Midlands region of England, and the lesson lasted $60 \mathrm{~min}$. Overall, the plan was adhered to closely. For the first $4 \mathrm{~min}$ of the research lesson, the teacher asked students to recall the problem they tackled previously. He displayed a diagram of someone giving an injection: 'Talk to the person next to you about the task from last lesson. What was the task? Can you remember any of the facts and figures?' Students discussed the task in pairs. The teacher then gave out both the task and the students' initial responses. For the next 5 min, he asked students to read the feedback questions and respond to these in writing.

Then, the teacher asked students to put down their pens: 'Explain your thoughts to your partner: What you've done, how you've done it and how far you got'. Students had good descriptive conversations, but the teacher felt they could justify their decisions more carefully, so he prompted them to do this (this was anticipated in row 3 of Table 2). After a little more time developing their approaches, the teacher introduced the changed constraints, explaining that vaccine A had now become $100 \%$ effective, but was more expensive, while vaccine B had the same effectiveness but was cheaper (Table 1; Fig. 4): 'What I want you to do now is just discuss with your partner first of all what's changed but how does this change the overall picture, so how does this impact our solution, how does this change the problem'.

Immediately, one student exclaimed: 'I did all that work for no reason!' The teacher responded that this was just what would happen in reality: 'No! In real life things change all the time'. While some students began the problem again, others adjusted their initial solution by looking at the differences between the costs. Students were allowed to work at the problem, uninterrupted, for $20 \mathrm{~min}$. At this point, the teacher decided to review one of the strategies that was being used. Six pairs of students had decided to vaccinate exactly $50 \%$ of the people in each category. The teacher probed their reasoning and asked whether they had considered how much money would be left. He used this example to prompt everyone to explain their reasoning more clearly on their poster: 'Put down all the steps you were taking'.

Students were now given a further $11 \mathrm{~min}$ to work on the problem before the final plenary discussion. The teacher continued to encourage students to take account of the budget available. Towards the end of the lesson, the teacher held a 5-min whole-class discussion. He pointed out the range of approaches in evidence and selected two solutions to discuss with the class. He presented a tabular approach that one pair had started and suggested that this might be an approach others could take up. He then asked a second pair of students to describe their approach. They explained how they had allocated money in the ratio of 1:4 to the vaccines $A$ and $B$ and calculated how many people would be saved. They

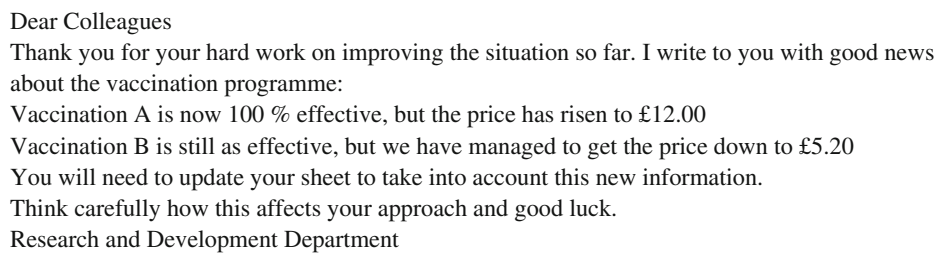

Fig. 4 Information revealed to the class to stimulate a shift in strategic thinking 
then tried to vaccinate more people using the same approach and realised that everyone could be vaccinated. The teacher commended the pair on keeping in mind both the goal (maximising the number of survivors) and the budget. Others, he pointed out, had focused on prioritising who was to be vaccinated and had lost sight of the budget. This is where the lesson ended.

\section{The post-lesson discussion}

The post-lesson discussion lasted $75 \mathrm{~min}$ and was held in the same classroom immediately following the lesson. It involved the 18 people who had observed the lesson: the three teachers from the school, two teachers from other schools, three HE researchers (the authors of this article); two representatives from project funders; four Japanese visitors (a teacher, an administrator, an HE representative, and a translator); two $\mathrm{PhD}$ students and two academics. The discussion was chaired by one of us (Wake), and the role of 'knowledgeable other' was taken by another (Swan).

Much of the discussion focused on the specific interventions the teacher made and how these had affected the students' strategic planning and communication-the research foci for this lesson. Examples of questions that had been seen to encourage strategic planning behaviours were instructions to stop and talk: 'Put your pens down and tell each other what you are doing'; questions that focused attention on constraints: 'How do you know when the money will run out?', 'Could you do better than vaccinate everyone with B?' It was noted that such interventions had the effect of making students reconsider the whole direction of their work. Interventions that also had this effect were teacher instructions that promoted redrafting and explanation (e.g. 'Put down all the steps you were taking').

It was evident that the teacher had internalised both the anticipated issues table (Table 2) and the progression table (Table 3). In fact, the teacher apologised that he had not made more use of the questions in the anticipated issues table, but this was challenged by observers who pointed out that most of the questions asked in the lesson were close variants of the ones in the table. He had also clearly used the progression table to select the student approaches to be discussed in the final plenary. One was chosen to focus on planning, in particular of the need to focus on the constraints of the problem; the other was chosen to focus on communication, in particular the power of organising and presenting the approach using a structured table.

The professional learning that emerged from the discussion thus concerned the detailed pedagogical interventions that the teacher had made to foster strategic planning and communication. The anticipated issues table and the progression table were particularly powerful in promoting this focus both in the planning and during the lesson. They enabled teachers to plan formative interventions that would potentially encourage students to develop these processes, and this enabled the post-lesson discussion to identify interventions that were effective. The discussion also identified the two different strategies adopted by students: allocating resources first, then checking whether the budget had been exceeded; or first deciding the greatest number of vaccines that could be purchased and only then allocating them. The first strategy results in an iterative trial and improvement approach, while the second offers an efficient direct solution. Such strategies are common in resource allocation problems. The participants were thus able to consider how one planning strategy might be developed into a much more powerful one. The discussions highlighted how the research lessons had allowed detailed observation of student responses in ways that teachers did not usually, if ever, have opportunities to experience. The ensuing discussions of strategy and pedagogy, the teachers informed us, occur only rarely in their 
professional lives, and they rated participation in lesson study in general, and this research lesson in particular, as particularly formative for them.

\section{Analysis}

In our analysis from a CHAT perspective, we find the ideas associated with artefacts, instruments, and boundary objects (introduced earlier) fundamental in understanding the facilitation of the learning of students in the classroom and the professional learning of the lesson-study group.

In the planning phase, the final lesson plan as a documentary artefact turned out to be considerably more substantial than the usual plans that teachers might typically produce for a lesson. Indeed, Japanese colleagues liken a lesson plan to a research proposal that guides the group's investigations into their didactical design. The 'Outbreak' plan was 10 pages, incorporating the anticipated issues and progression tables, in addition to much further detail, including careful sequencing of planned teacher actions. The identification of research questions in the lesson plan is important in defining the pedagogies that the planning group envisage will lead to the desired learning outcomes. For example, the strategy of asking pairs of students to explain the strategic approaches they had used in the pre-lesson phase was designed to encourage planning activity by the students and enable the lesson-study group to gather evidence for analysis in the post-lesson discussion. Likewise, the introduction of the change in constraints in a planned intervention during the lesson is an example of an artefact that was designed to be made instrumental in its use by the teacher in the lesson. During the lesson, the teacher had to assess exactly when to make this intervention, based on his judgment of students' progress, with this decision being informed by his comparison of outcomes with those in the anticipated issues table of the lesson plan.

Such examples of the selection and integration of artefacts into the lesson during the planning phase correspond to the didactical configuration and exploitation modes in the theory of instrumental orchestration as elaborated by Drijvers et al. (2010). In this theory, lessons are seen as orchestral performances, with the didactical performance phase relating to the lesson implementation. During the lesson, the artefacts that the lesson-planning group had identified and written into their lesson plan, considered as a script for the lesson, were made instrumental in their use, either by the teacher (e.g. the anticipated issues table) or by the students (e.g. the modified vaccine information). Such careful planning allows for instrumental genesis, in Drijver et al.'s terms, that is, the artefact becomes an instrument that both shapes the thinking of the user (the instrumentation process) and is in itself shaped by the user (the instrumentalisation process).

Working with blank anticipated issues (Table 2) and progression (Table 3) tables (the two artefacts introduced by us as the research team) to develop bespoke artefacts for instrumental use in the classroom by the lead teacher for a particular research lesson involves the group in both instrumentation and instrumentalisation. The thinking of the group is shaped by the artefacts, as indeed the artefacts, during their design for the specific lesson, are themselves shaped by the group. This is shown in Table 2, for example, which shows the outcomes of the planning group's thinking about how students at this stage in their mathematics curriculum are likely to handle strategic approaches to solving the problem at hand. Likewise, Table 3 shows the group's thinking regarding how students will perform at one of four levels in relation to their strategic approach and how they will 
communicate this. In relation to these two aspects of problem solving, the group also considered what questions they might ask to assist students in progressing from one level to the next. The completion of these tables provides key moments of instrumental genesis in the work of the lesson-study group Activity System which are important in stimulating (in this case professional) learning. The learning is not only individual but also collaborative and communal: Beach (1999) considers the new relationships that the individual develops with the social activity of a group as being important in identity development and learning. Teachers in the interviews we conducted often refer to such personal development and value the richness of the discussion facilitated by the different professional experiences that members of the group contribute.

The anticipated issues and progression tables, therefore, serve not only to support actions in the classroom activity system; they also, in the lesson-study group, act as catalysts for reflection on, and development of, professional knowledge in anticipation of how to respond to likely student behaviours. In the case of the progression table, this is in relation to key processes, as highlighted by the research question for the lesson, and in the case of the anticipated issues table, this is in relation to student actions more widely. Consequently, these tables as artefacts have important roles to play as part of the lesson plan considered as a boundary object, facilitating teacher actions in, and group reflections on, the research lesson. Blank anticipated issues and progression tables can be considered as a general class of artefact (document) that invokes instrumentalisation and instrumentation processes as the planning team goes about bringing each into instrumental use in their preparation for specific problem-solving lessons. The use of the professional understanding that is embodied in the tables as they are tailored to a specific lesson in the postlesson discussion facilitates reflection on their use in the classroom by a teacher of the group, and, importantly, beyond this during further cycles of enquiry as new bespoke versions are designed: involvement in ongoing cycles of enquiry in lesson study allows for professional learning in relation to a particular lesson to be generalised so as to inform the specifics of future lessons. Thus, we see the anticipated issues and progression tables as having distinct and particularly effective roles to play within the overall lesson plan and in facilitating lesson-study group activity in each phase of its activity.

As we illustrate in the account of our case study, the anticipated issues and progression tables and overall lesson plan play important roles as artefacts in supporting and facilitating both teaching of students and learning of teachers. Each has an important but different role to play in the two activity systems: in the lesson-study group, they prompt collaborative thinking regarding student responses and potential student learning, and in the classroom, they provide the teacher with insight into the collective wisdom of the group as to how to respond to this. Thus, these artefacts as boundary objects facilitate boundary crossing in ways that are designed to enable professional learning. Further, we highlight the structure of the lesson plan in this context: as in the case of the anticipated issues and progression tables, an outline lesson plan has been introduced by the university team to support the planning of specific lessons. We have found that the cyclical use, moving from general to specific forms, is particularly powerful in prompting reflection on the interplay between professional knowledge and practice.

It is perhaps not surprising that we found ourselves intervening and introducing the lesson-plan structure and tables for the consideration of the planning group, as much of our work is focused on designing tasks, lessons, and indeed associated professional learning. Our involvement as mathematics academics in other professional Activity Systems brings a focus on professional learning to the lesson-planning group and how we might design for this. As we have shown, our use of the theoretical lens of CHAT and the constructs 
discussed here have helped us to do so in ways that encourage genuine collaboration between teachers and academics. This is demonstrated in the case study by the instance when the planning of the change in constraints during the lesson was initiated by the lead teacher and defended robustly when questioned by the university team.

We have already drawn attention to the interaction of the two activity systems of classroom and lesson-study group, and have to this point neglected our own interaction as researchers. In this article, we have emphasised the importance of the artefacts that we have identified in facilitating professional learning in the lesson-study process. However, we consider these as necessary but not sufficient for professional learning to take place. Also of importance is the input of expertise regarding (i) the lesson-study process and (ii) problem solving, as well as sensitivity to the emerging needs of the lesson-study group in relation to professional learning in these areas. This expertise has largely been provided by the research team in the first phase of our research, but our withdrawal and support of alternative provision is fundamental to the research questions regarding scalability, sustainability, and support that underpin our ongoing work.

\section{Conclusions}

Our research into lesson study for problem solving in mathematics highlights how a task provides only a starting point for teacher and student engagement in classroom activity. Further, and central to professional learning, as well as an outcome of the process of lesson study, our attention is drawn to the research lesson plan as a boundary object that has different utility and purpose in the activities of the lesson-planning group and the school classroom, viewed as Activity Systems. The research lesson plan is produced during the planning phase of the activity of the lesson-study group and, as such, provides an image of the intended lesson, incorporating artefacts identified by the lesson-planning team and sequenced by them for use in the research lesson. These artefacts relate not only to the actions of the students but also to those of the teacher, with a range of different pedagogies, as the teacher brings them into instrumental use in their classroom practice. We note the particular importance of the blank 'anticipated issues' and 'progression' tables elements of the research lesson plan as boundary objects. We view these as a general class of artefact that at the planning phase involve teachers and academics in both instrumentalisation and instrumentation processes, as they populate these tables with anticipated issues and desired student behaviours (progression). In doing so, teachers' collaborative and emerging thinking regarding how students will respond to, and learn as a result of, their didactical design is considered carefully and documented. Following completion, these artefacts (anticipated issues and progression tables) provide important insights into fundamental aspects of the planning team's image of the research lesson, which is embodied in the overall lesson plan. The post-lesson discussion can then draw on the lesson plan to hold a mirror to intentions and expectations that can be contrasted with the actual outcomes of the lesson. As is often noted in relation to lesson study, the post-lesson discussion exploits the team's comparison of their jointly agreed intentions and actual enactment as a helpful way of promoting joint responsibility of the group for the lesson outcomes, rather than attributing these to the lead teacher. Our analysis suggests that artefacts such as the anticipated issues and progression tables are important in facilitating this collaboration and joint responsibility as well as stimulating professional learning. 
As academics with both research and design roles, our own professional learning has been facilitated by our involvement as part of the lesson-planning team, allowing us to understand better how tasks are enacted in classrooms by teachers in pursuit of learning outcomes in relation to problem solving. In this article, however, we demonstrate how our understanding of the different activity systems that are part of the lesson-study process has provided insight into how to support professional learning by the design of artefacts that facilitate instrumentalisation and instrumentation processes by the lesson-study group. As we have indicated, the research lesson plan may be considered as a document of this type, and at a finer grain size, we highlight how the level of detail required in completion of the anticipated issues and progression tables facilitates similar processes and prompts more indepth thinking in relation to teaching and learning. Our future research intends to focus further on how teachers move from their general understanding of the issues that these tables address to their particular application for specific lessons. We also intend to consider whether, in collaboration with teacher colleagues, we might design other documents of this type that might support other aspects of professional learning. We recognise that ensuring that lesson-study groups are supported by external, research-informed expertise presents a particular challenge, and this is central to thinking in our current work. As part of this, we are developing a toolkit to support professional learning through lesson study, and the research and the theoretical understanding we present and develop here have an important role to play in providing insight into how to proceed.

Acknowledgments The work described in this article was funded by the Bowland Charitable Trust and the Nuffield Foundation. We are grateful to our IMPULS colleagues from Tokyo Gakugei University for their expert involvement and to all of the teachers who took part in the project.

Open Access This article is distributed under the terms of the Creative Commons Attribution 4.0 International License (http://creativecommons.org/licenses/by/4.0/), which permits unrestricted use, distribution, and reproduction in any medium, provided you give appropriate credit to the original author(s) and the source, provide a link to the Creative Commons license, and indicate if changes were made.

\section{References}

Akkerman, S. F., \& Bakker, A. (2011). Boundary crossing and boundary objects. Review of Educational Research, 81(2), 132-169.

Beach, K. D. (1999). Consequential transitions: A sociocultural expedition beyond transfer in education. Review of Research in Education, 24, 101-139.

Boland, R. J., \& Tenkasi, R. V. (1995). Perspective making and perspective taking in communities of knowing. Organization Science, 6(4), 350-372.

Daniels, H. (2001). Vygotsky and pedagogy. Abingdon, UK: RoutledgeFalmer.

Doig, B., \& Groves, S. (2012). Japanese lesson study: Teacher professional development through communities of inquiry. Mathematics Teacher Education and Development, 13(1), 77-93.

Drijvers, P., Doorman, M., Boon, P., Reed, H., \& Gravemeijer, K. (2010). The teacher and the tool: Instrumental orchestrations in the technology-rich mathematics classroom. Educational Studies in Mathematics, 75(2), 213-234.

Drijvers, P., \& Trouche, L. (2008). From artifacts to instruments: A theoretical framework behind the orchestra metaphor. In G. W. Blume \& M. K. Heid (Eds.), Research on technology and the teaching and learning of mathematics (cases and perspectives (Vol. 2, pp. 363-392). Charlotte: Information Age.

Engeström, Y. (2001). Expansive learning at work: Toward an activity theoretical reconceptualization. Journal of Education and Work, 14(1), 133-156.

Engeström, Y., \& Cole, M. (1997). Situated cognition in search of an agenda. In J. A. Whitson \& D. Kirshner (Eds.), Situated cognition: Social, semiotic, and psychological perspectives (pp. 301-309). Hillsdale, NJ: Lawrence Erlbaum Associates. 
Engeström, Y., Engeström, R., \& Kärkkäinen, M. (1995). Polycontextuality and boundary crossing in expert cognition: Learning and problem solving in complex work activities. Learning and Instruction: An International Journal, 5, 319-336.

Fernandez, C., \& Yoshida, M. (2004). Lesson study: A Japanese approach to improving mathematics teaching and learning. Mahwah, NJ: Lawrence Erlbaum Associates.

Foster, C., Wake, G., \& Swan, M. (2014). Mathematical knowledge for teaching problem solving: Lessons from lesson study. In S. Oesterle, P. Liljedahl, C. Nicol \& D. Allan (Eds.), Proceedings of the Joint Meeting of PME 38 and PME-NA 36 (Vol. 3, pp. 97-104). Vancouver: PME.

Joubert, M., \& Sutherland, R. (2009). A perspective on the literature: CPD for teachers of mathematics. Sheffield: NCETM. Retrieved June 2015 from www.ncetm.org.uk/enquiry/15009.

Kindon, S., Pain, R., \& Kesby, M. (2007). Participatory action research approaches and methods: Connecting people, participation and place. London: Routledge.

Knights, C. \& Zorn, J. (2008). Outbreak. Bowland maths. Retrieved June 2015 from www.bowlandmaths. org.uk/projects/outbreak.html.

Lewis, C., Perry, R., \& Murata, A. (2006). How should research contribute to instructional improvement? The case of lesson study. Educational Researcher, 35(3), 3-14.

McIntyre, A. (2008). Participatory action research. London: Sage Publications Ltd.

National Council of Teachers of Mathematics (NCTM). (2000). Principles and standards for school mathematics. Reston, VA: NCTM.

OECD (Organisation for Economic Co-operation and Development). (2003). The PISA 2003 assessment framework-mathematics, reading, science and problem solving knowledge and skills. Paris: OECD.

Qualifications and Curriculum Authority. (2007). Mathematics: Programme of study for key stage 3 and attainment targets. London: Qualifications and Curriculum Authority.

Roth, W.-M., \& Radford, L. (2011). A cultural-historical perspective on mathematics teaching and learning (Vol. 2). Rotterdam: Sense Publishers.

Schön, D. A. (1983). The reflective practitioner: How professionals think in action. New York: Basic Books.

Shimizu, Y. (1999). Aspects of mathematics teacher education in Japan: Focusing on teachers' roles. Journal of Mathematics Teacher Education, 2(1), 107-116.

Star, S. L., \& Griesemer, J. R. (1989). Institutional ecology, "translations" and boundary objects: Amateurs and professionals in Berkeley's Museum of Vertebrate Zoology, 1907-1939. Social Studies of Science, 19(3), 387-420.

Stigler, J. W., \& Hiebert, J. (1999). The teaching gap: Best ideas from the world's teachers for improving education in the classroom. New York: Free Press.

Wake, G., Foster, C., \& Swan, M. (2013). A theoretical lens on lesson study: Professional learning across boundaries. In A. M. Lindmeier \& A. Heinze (Eds.), Proceedings of the 37th Conference of the International Group for the Psychology of Mathematics Education (Vol. 4, pp. 369-376). Kiel: PME.

Wake, G., Foster, C., \& Swan, M. (2014). Teacher knowledge for modelling and problem solving. In S. Pope (Ed.), Proceedings of the 8th British Congress of Mathematics Education, April 2014 (Vol. 34, no. 2, pp. 335-342). University of Nottingham. 